\title{
The new Ghana mental health bill
}

\author{
Akwasi O. Osei, ${ }^{1}$ Mark Roberts ${ }^{2}$ and Jim Crabb ${ }^{3}$
}

${ }^{1}$ Chief Psychiatrist, Ghana Health Service; Medical Director, Accra Psychiatric Hospital, Accra, Ghana, email akwasiosei@yahoo.com ${ }^{2}$ Consultant Forensic Psychiatrist, Ravenswood House, Knowle, Fareham, UK, email mark.roberts@hantspt-sw.nhs.uk ${ }^{3}$ ST5 Registrar in Liaison Psychiatry, Southern General Hospital, Glasgow, UK, email Jim.Crabb@ggc.scot.nhs.uk

\begin{abstract}
n Ghana, the main burden of ill-health, as in many sub-Saharan countries, consists of communicable disease, illnesses due to inadequate nutrition and poor reproductive health. As these conditions are tackled, other diseases, such as mental disorders and substance misuse, are also becoming the focus of development efforts. In Ghana, it has been estimated that there are 2166000 individuals experiencing a mild to moderate mental disorder, with a further 650000 suffering from a severe mental disorder, out of a population of 21.6 million (World Health Organization, 2007). In 2003, the country's mental health workforce consisted of 9 psychiatrists (only 4 of whom worked in mental health services), 451 nurses and 160 community psychiatric nurses (World Health Organization, 2003). Currently there are just 5 consultant psychiatrists in active service in the public sector and 11 retired psychiatrists. As just under 33000 individuals are seen each year in Ghana by mental health services, there is an estimated treatment gap of $98 \%$ (World Health Organization, 2007). Most mental healthcare is undertaken at the three large psychiatric hospitals, in the south of the country. This is reflected in the ratio of out-patient attendance to admission, which is 4.64 for mental health, compared with 14.6 for all health conditions (Ghana Health Service, 2005).
\end{abstract}

\section{Current state of mental health legislation in Africa}

Across Africa, 11 countries (20\% of the continent's total) are known currently to have no mental health law. Of those that do have legislation, 18 (33\%) have mental health acts that date from before 1961. A further $8(15 \%)$ have laws from the decades 1962-71 and 1972-81, while only 16 (30\%) have legislation dating from 1991 to the present (World Health Organization, 2005). There has been variable development of mental health law in western sub-Saharan countries. As might be expected, low-income countries such as Niger and Benin, which come near the bottom in ranking on the Human Development Index (United Nations, 2008), have legislation dating from the first half of the last century. In some cases, however, there is a marked disparity between a nation's 'development' and its provision of mental health law. Nigeria, which ranks 154th out of 179 in terms of its Human Development Index, has mental health law dating from the 1940s, while Burkina Faso, which ranks 173rd, has legislation dating from just over 10 years ago. Ghana, like other countries in the region, such as Senegal, currently has outdated legislation from 1972.

\section{Mental health legislation in Ghana}

Mental health legislation began in Ghana in 1888, when a Lunatic Asylum Ordinance was passed. This empowered the authorities to arrest and detain as special prisoners vagrant people with a mental illness, which in turn led to the building of Accra Asylum in 1906 (the Asylum has since become Accra Psychiatric Hospital). There was no revision of the legislation until 1972, when a Mental Health Decree (known as the NRCD 30) was passed. This was a more progressive piece of legislation, in that it recognised that those with mental illness should not be prisoners but patients who require treatment. Even so, the NRCD 30, which recognised as mentally ill only persons residing in psychiatric hospitals, made no mention of human rights and required no oversight of treatment. The Decree did prescribe the establishment of a Mental Health Tribunal; however, this was never actually done. Therefore patients do not currently have any independent organisation from which to seek redress if they are involuntarily detained. At present, patients, if they feel aggrieved (and have the means), report to the Commission for Human Rights and Administrative Justice (CHRAJ) or to the office of the President. In both cases the response of the hospital authorities is usually enough to resolve the case (usually with detention being upheld). The visiting committees called for by the Decree have similarly never been established.

Although some efforts have been made by bodies such as the CHRAJ to monitor in-patient standards periodically, in reality facilities are currently not monitored and those involved have no accountability for the care they provide to individuals with mental disorder under current legislation.

In Ghana, prayer camps and traditional healers see far more cases of mental illness than the three psychiatric hospitals. Individuals held involuntarily in these settings are not afforded any protection under current legislation.

The 1972 Decree defines the conditions for involuntary detention of forensic cases; however, in reality even unwilling and aggressive individuals are admitted as 'voluntary' patients as long as there is the consent of relatives. Once admitted, it is often difficult for forensic patients to leave the hospital system. Even those who have recovered and are fit 
to plead in court have remained in hospital for as long as 20 years because the courts do not recall them and there is no mechanism for automatic release into the community.

\section{The new Ghana mental health bill}

The new bill will have two main effects: first, it provides a legal framework for the safe management of patients; and second, it establishes an authority to govern mental health services. Under the 1972 legislation, people with a mental illness were defined as those residing in psychiatric hospitals. The new Ghana mental health bill changes this to include the majority of those in the community who are mentally ill. The new bill emphasises community rather than institutional care. This is important because in Ghana, as in many low-income countries, most funding is spent on institutional care (Hyman et al, 2006), and by moving care into the community the new act will allow resources to be redirected. It is hoped that this redistribution will allow more individuals to access care, and start to reduce the mental health treatment gap.

The new bill establishes a mental health tribunal to adjudicate on alleged cases of abuse, in order to protect both service users and mental health staff. It will cover traditional and faith-based settings as well as psychiatric facilities. The bill criminalises human rights abuses such as flogging, forced fasting and discrimination. Visiting committees will be established with the primary function of protecting the rights of people with mental disorder. Yearly inspections of facilities will be mandatory.

The bill clearly spells out for the first time the rights of people who are mentally ill, explicitly highlighting their right to marriage, employment, accommodation and vote. The principle of non-discrimination is core to the legislation, with protection for vulnerable groups in Ghanaian society such as women, children and the elderly. Individuals with intellectual disability or incapacity are safeguarded through guardianship.

The legislation establishes minimum standards of care and makes specific funding available for this. It is hoped that these measures, and the influence of the new Mental Health Board, will help ease the problems of inadequate drug supply and lack of recruitment and retention of mental health workers. The establishment of the Board to oversee mental health services is an internal mechanism which will ensure the bill is implemented. Specifically, it will ensure that the administrative structures like mental health tribunals and visiting committees are established and function in practice.

\section{Challenges in bringing the new act into effect}

Just after the millennium, the World Health Organization (2001) commenced a programme to strengthen mental health legislation in low- and middle-income countries. In response to this, in early 2004 a technical drafting committee was formed by the Minister of Health in Ghana, supported by a team from the World Health Organization. A wide range of stakeholders, including mental health and general health workers, legal experts, traditional and faith healers and teachers, were consulted during the initial drafting of the new act. It went through 19 drafts before proving acceptable to all parties. Since January 2006 the new mental health act has been waiting to progress through parliament. During 2009, the Ministry of Health made two significant retreats to resolve all outstanding issues concerning the mental health bill and other legislation, and has now decided to present the bill as part of a more general health service bill.

\section{Conclusions}

We would encourage countries with outdated mental health legislation to redress the rights of those with mental illness in their locality. Change is by no means easy. Producing new legislation is arduous: it requires patience and diplomacy. Any new legislation has to be considered in the widest context, with care taken to examine the impact and interrelationships with other legislation and systems. There will always be the need to manage the expectations of service users and health professionals while the drafting and implementation of new legislation take place. Advocacy work is needed to keep the rights of those with mental illness high on the political agenda. Various agencies, including non-governmental organisations and the media, are of help in this task. International publications can also help to raise awareness.

The developments we have described in Ghana provide hope and optimism. Ghana has taken positive steps to support and protect those who have mental illness. In Ghana today the majority of this hard work has been done, a document has been drafted and is ready to pass into law.

\section{References}

Ghana Health Service (2005) Annual Report 2005. Ghana Health Service. Hyman, S., Chisholm, D., Kessler, R., et al (2006) Mental disorders. In Disease Control Priorities in Developing Countries (2nd edition) (eds T. Jamison, D. T. Breman \& J. G. Measham), ch. 31. Oxford University Press.

United Nations (2008) Human Development Indices. UNDP. Available at http://hdr.undp.org/en/media/HDI_2008_EN_Tables.pdf (accessed April 2009).

World Health Organization (2001) Mental Health Policy Project - Policy and Service Guidance Package - Executive Summary. WHO.

World Health Organization (2003) Mental Health Profile 2003. WHO. Available at http://www.who.int/countries/gha/publications/MENTAL HEALTH_PROFILE.pdf (accessed April 2009).

World Health Organization (2005) Project Atlas: Resources for Mental Health and Neurological Disorders. WHO. Available at http://www. who.int/globalatlas/default.asp (accessed April 2009).

World Health Organization (2007) Ghana Country Summary. WHO. Available at http://www.who.int/mental_health/policy/country/ GhanaCoutrySummary_Oct2007.pdf (sic; accessed April 2009). 